\title{
Nucleosynthesis in novae: experimental progress in the determination of nuclear reaction rates
}

\author{
Alain Coc \\ CSNSM, CNRS/IN2P3, Université Paris Sud, Bâtiment 104, F-91405 Orsay Campus, France
}

\begin{abstract}
The sources of nuclear uncertainties in nova nucleosynthesis have been identified using hydrodynamical nova models. Experimental efforts have followed and significantly reduced those uncertainties. This is important for the evaluation of nova contribution to galactic chemical evolution, gamma-ray astronomy and possibly presolar grain studies. In particular, estimations of expected gamma-ray fluxes are essential for the planning of observations with existing or future satellites.
\end{abstract}

Keywords: Nuclear Astrophysics, Novae

PACS: $26.30 . \mathrm{Ca}, 26.50 .+\mathrm{x}$

\section{INTRODUCTION}

Novae are thermonuclear runaways occurring at the surface of a white dwarf accreting hydrogen rich matter from its companion in a close binary system[1, 2, 3, 4]. Material from the white dwarf ${ }^{12} \mathrm{C}$ and ${ }^{16} \mathrm{O}$ (CO nova) or ${ }^{16} \mathrm{O},{ }^{20} \mathrm{Ne}$ plus some $\mathrm{Na}, \mathrm{Mg}$ and $\mathrm{Al}$ isotopes (ONe nova) provide the seeds for the operation of the $\mathrm{CNO}$ cycle and further nucleosynthesis. Novae are supposed to be at the origin of galactic ${ }^{15} \mathrm{~N}$ and ${ }^{17} \mathrm{O}$ and contribute to the galactic chemical evolution of ${ }^{7} \mathrm{Li}$ and ${ }^{13} \mathrm{C}$. In addition they produce radioactive isotopes that could be detected by their gamma-ray emission: ${ }^{7} \mathrm{Be}(478 \mathrm{keV})$, ${ }^{18} \mathrm{~F}(\leq 511 \mathrm{keV}),{ }^{22} \mathrm{Na}(1.275 \mathrm{MeV})$ and ${ }^{26} \mathrm{Al}(1.809 \mathrm{MeV})$. The yields of these isotopes depend strongly on the hydrodynamics of the explosion but also on nuclear reaction rates involving stable and radioactive nuclei. Tests of sensitivity to the reaction rates uncertainties have been done using parametrized[5], semi-analytic[6], post-processed[7] nova models but also with a 1-D hydrodynamical model. Indeed, in a series of papers the impact of nuclear uncertainties in the hot-pp chain[8], the hot-CNO cycle[9], the $\mathrm{Na}-\mathrm{Mg}-\mathrm{Al}$ region[10] and $\mathrm{Si}-\mathrm{Ar}$ region[11] have been investigated with the Barcelona (SHIVA) hydrocode. In this way, the temperature and density profiles, their time evolution, and the effect of convection time scale were fully taken into account. The nuclear reaction rates whose uncertainties affected most nova nucleosynthesis having been identified, many nuclear physics experiments were conducted to reduce these uncertainties. In this review, we will shortly summarize the experimental progress made in this domain.

\section{HOT CNO CYCLE}

The hot-CNO cycle deserves special attention as it is the main source of energy for both type of novae and is the source for the production of ${ }^{13} \mathrm{C},{ }^{15} \mathrm{~N},{ }^{17} \mathrm{O}$ (galactic 
chemical evolution) and ${ }^{18} \mathrm{~F}$ (gamma-ray astronomy). The positrons produced by ${ }^{18} \mathrm{~F}$ $\beta^{+}$decay annihilate and are the dominant source of gamma rays during the first hours of a nova explosion[12]. Following a series of hydrodynamical calculations, major nuclear uncertainties on the production of ${ }^{17} \mathrm{O}$ and ${ }^{18} \mathrm{~F}$ were pointed out in Ref. [9] (hereafter CJHT).

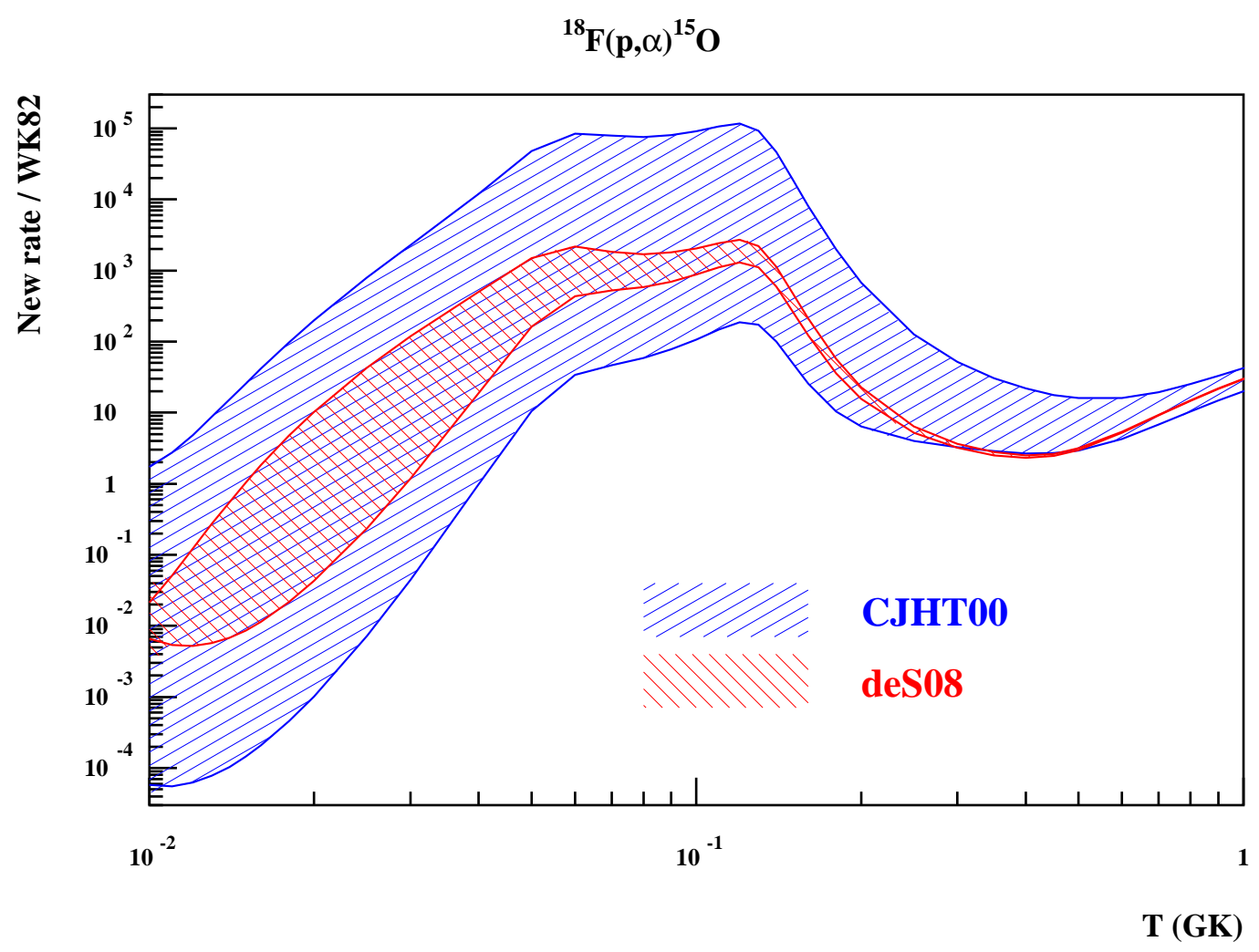

FIGURE 1. Reduced relative uncertainty [18] on the ${ }^{18} \mathrm{~F}(\mathrm{p}, \alpha){ }^{15} \mathrm{O}$ reaction rate. (An update of Fig. 6 in CJHT[9].)

In particular, the ${ }^{18} \mathrm{~F}(\mathrm{p}, \alpha){ }^{15} \mathrm{O}$ reaction was recognized as the main source of uncertainty for the ${ }^{18} \mathrm{~F}$ production, due to the unknown contributions of two low energy resonances. They are postulated at 8 and $38 \mathrm{keV}$ following the spectroscopic work of Utku et al.[13] who identified two ${ }^{19} \mathrm{Ne}$ levels at $E_{X}=6.419$ and $6.449 \mathrm{MeV}$ and assumed that they are the analogs of the $E_{X}=6.497$ and $6.528 \mathrm{MeV} \mathrm{3/2}+{ }^{19} \mathrm{~F}$ levels. Two (d,p) transfer reaction experiments, in inverse kinematics with a ${ }^{18} \mathrm{~F}$ beam, were conducted at Louvain-la-Neuve (LLN) [14] and Oak-Ridge (ORNL)[15]. They enabled to extract the neutron spectroscopic factor(s) of the (experimentally unresolved) ${ }^{19} \mathrm{~F}$ analog levels. Since the one to one assignments of these analog levels separated by only $30 \mathrm{keV}$ is not settled, even when assuming the equality of spectroscopic factors between analog levels, it is not possible yet to determine the two resonance relative contributions. However, the extracted spectroscopic factor value imply that they must be included in the calculation of the reaction rate.

In addition, if the spin and parity assignment is correct they should interfere with an 
other $3 / 2^{+}$broad resonance located at $E_{R}=665 \mathrm{keV}$. This latter resonance and the 330 $\mathrm{keV}, 3 / 2^{-}$have been precisely measured directly[16, 17] at ORNL and LLN. Interferences between the 8,38 and $665 \mathrm{keV}$ are expected to have a maximum effect right in the energy range of interest for nova. It is hence extremely important to determine their constructive or destructive nature. Until recently, the only constraint in this energy region was provided by an off-resonance measurement[17] at $380 \mathrm{keV}$ with a large error bar. A new direct measurement of the ${ }^{18} \mathrm{~F}(\mathrm{p}, \alpha){ }^{15} \mathrm{O}$ cross section was recently performed at LLN[18] at $E_{C M}=726,666,485$ and $400 \mathrm{keV}$. The higher energies correspond to the top of the $665 \mathrm{keV}$ resonances while the lower ones with respectively 180 and 35 counts are located close to the limit of the interference region. With these new results, R-matrix calculations including up to four $3 / 2^{+}$levels were performed to help constrain the $\mathrm{S}-$ factor. Even though more experiments are needed in the interference region, when taking into account those recent measurements[14, 15, 17, 18] the reduction of the uncertainty on the ${ }^{18} \mathrm{~F}(\mathrm{p}, \alpha){ }^{15} \mathrm{O}$ reaction rate is important as shown in Figure 1. In CJHT, the uncertainty on ${ }^{18} \mathrm{~F}$ production due to this reaction was a factor of $\sim 300$; it can now be estimated to a factor of $\sim 10$.

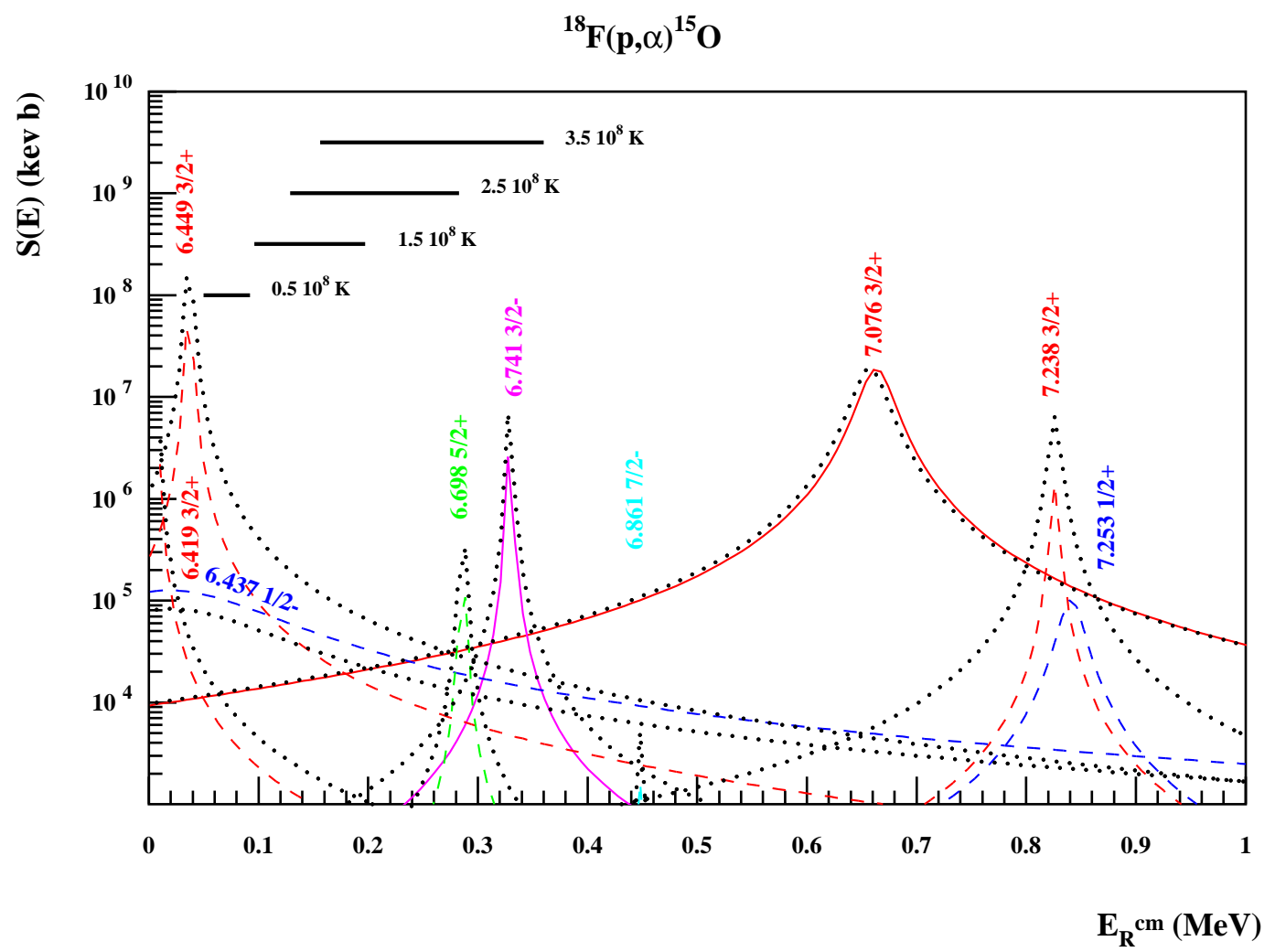

FIGURE 2. (On-line only.) Contributions of known ${ }^{19} \mathrm{~F}$ levels to ${ }^{18} \mathrm{~F}(\mathrm{p}, \alpha){ }^{15} \mathrm{O}$ astrophysical factor (color) compared to the previous situation (black dots) from Fig. 4 in CJHT[9].

We have up to now assumed that the reaction rate is dominated by the three $3 / 2^{+}$and the $3 / 2^{-}$resonances but the comparison with ${ }^{19} \mathrm{~F}$ spectrum suggest that several levels are missing in ${ }^{19} \mathrm{Ne}$. In particular two $1 / 2^{+}(\ell=0)$ broad levels have been predicted by 
microscopic[19] calculations, one at $\approx 1 \mathrm{MeV}$ above and another below threshold. If they exist they would lead to a significant contribution in the relevant energy range. Data analysis of an inelastic scattering experiment performed at LLN could provide information on this possible $\approx 1 \mathrm{MeV}$ level[20].

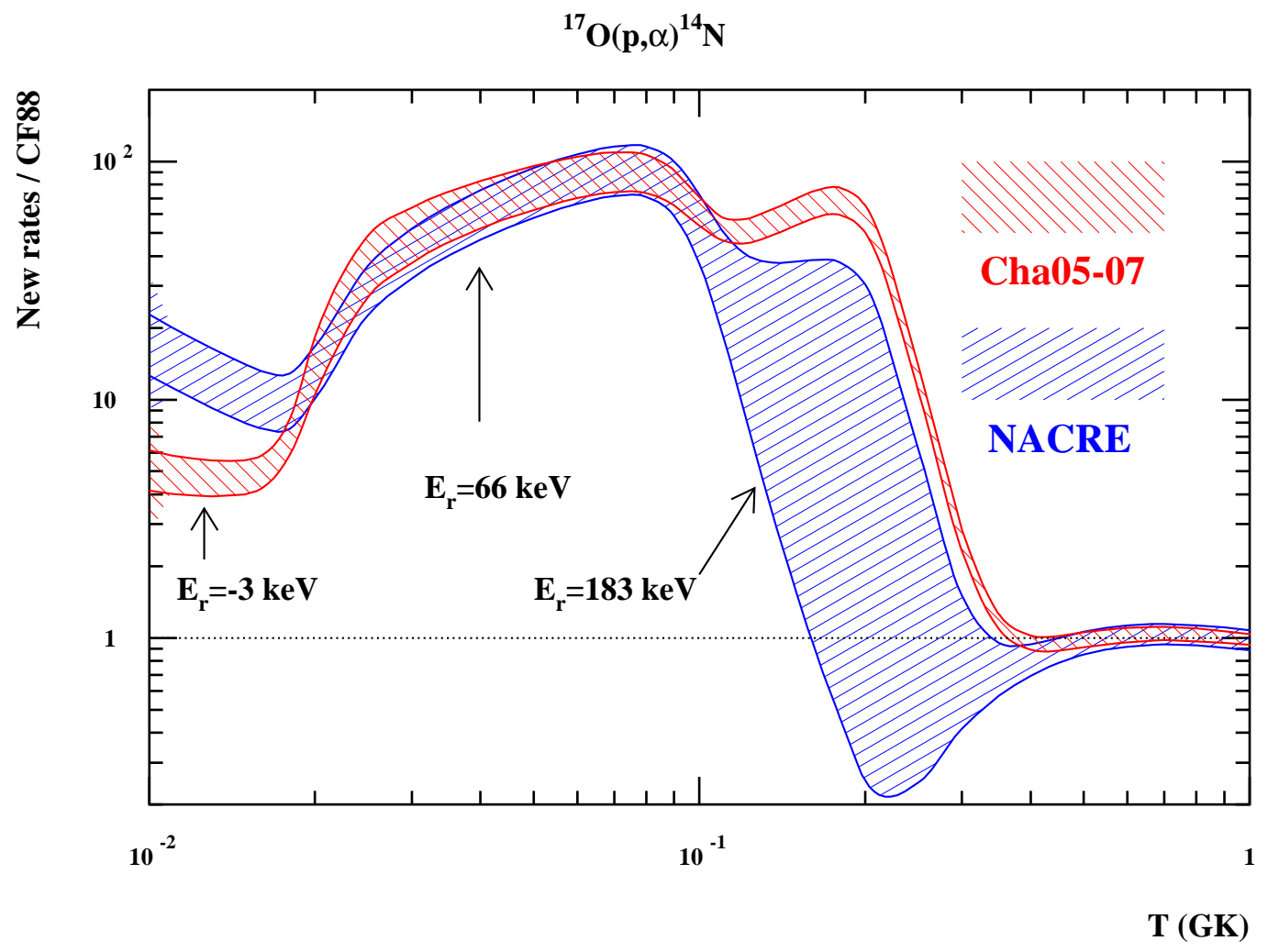

FIGURE 3. Reduced relative uncertainty on the ${ }^{17} \mathrm{O}(\mathrm{p}, \alpha){ }^{14} \mathrm{~N}$ reaction rate[22]. (An update of Fig. 8 in CJHT[9].)

The ${ }^{17} \mathrm{O}(\mathrm{p}, \alpha){ }^{14} \mathrm{~N}$ and ${ }^{17} \mathrm{O}(\mathrm{p}, \gamma){ }^{18} \mathrm{~F}$ reaction were also identified as sources of uncertainties for the production of ${ }^{18} \mathrm{~F}$. The latter leads to the formation of ${ }^{18} \mathrm{~F}$ from the ${ }^{16} \mathrm{O}$ seed nuclei trough the ${ }^{16} \mathrm{O}(\mathrm{p}, \gamma){ }^{17} \mathrm{~F}\left(\beta^{+}\right){ }^{17} \mathrm{O}(\mathrm{p}, \gamma){ }^{18} \mathrm{~F}$ chain while the former diverts the flow reducing both ${ }^{18} \mathrm{~F}$ and ${ }^{17} \mathrm{O}$ yields. According to the NACRE compilation[21], the uncertainty on these rates came from the, at that time unobserved, resonance around $190 \mathrm{keV}$ resulting in a factor of $\sim 10$ additional uncertainty on ${ }^{18} \mathrm{~F}$ production[9]. The NACRE rates were based on experimental data which were found to be inaccurate after several measurements performed first at LENA[23] and in Orsay[22]. There is now a good agreement, on the resonance energy (e.g. 183.2 $\pm 0.6 \mathrm{keV}[22])$ and (p, $\alpha)$ strength (e.g. $1.6 \pm 0.2 \mathrm{meV}[22]$ ) but a small discrepancy concerning the (p, $\gamma)$ strength (1.2 $\pm 0.2 \mu \mathrm{eV}[23]$ and 2.2 $\pm 0.4 \mu \mathrm{eV}[22])$.

Figures 3 and 4 display the evolution of the ${ }^{17} \mathrm{O}+\mathrm{p}$ rates since the NACRE compilation showing that they are now both known with sufficiently good accuracy for nova applications. At nova temperatures, the ${ }^{17} \mathrm{O}(\mathrm{p}, \gamma){ }^{18} \mathrm{~F}$ rate is lower while the ${ }^{17} \mathrm{O}(\mathrm{p}, \alpha){ }^{14} \mathrm{~N}$ rate is higher. As a result, the ${ }^{18} \mathrm{~F}$ and ${ }^{17} \mathrm{O}$ nova production is smaller. (See Fox et al.[23] 


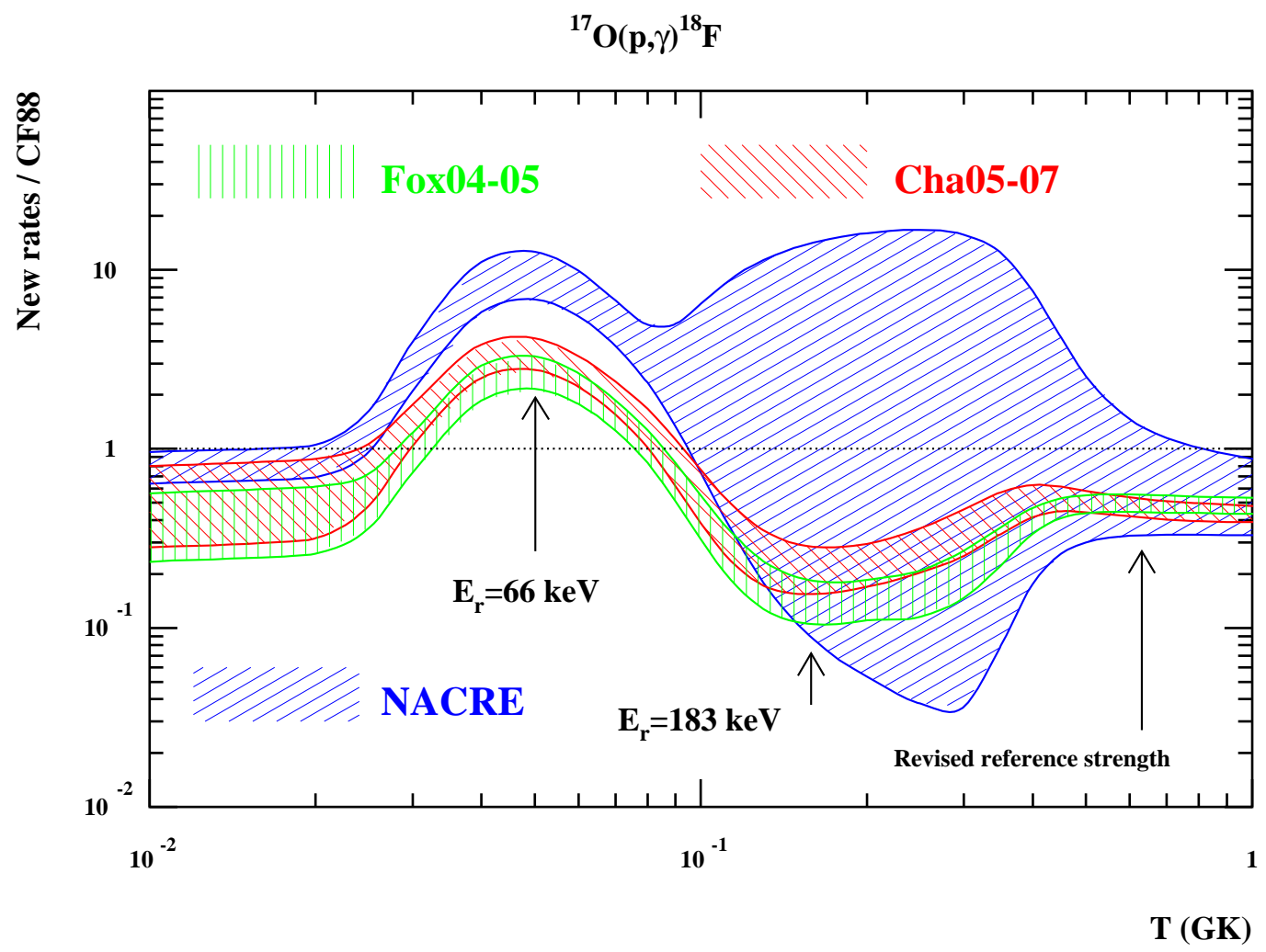

FIGURE 4. Reduced relative uncertainty according to Chafa et al.[22] or Fox et al.[23] on the ${ }^{17} \mathrm{O}(\mathrm{p}, \gamma){ }^{18} \mathrm{~F}$ reaction rate. (An update of Fig. 9 in CJHT[9].)

for reanalysis of of the $66 \mathrm{keV}$ and subthreshold resonance contributions.)

The reaction rates involved in ${ }^{18} \mathrm{~F}$ and ${ }^{17} \mathrm{O}$ are now much better known and new hydrodynamical calculations are underway to update their yields but also to better understand their nucleosynthesis.

\section{OTHER REGIONS OR REACTIONS}

Nuclear uncertainties on the production of ${ }^{7} \mathrm{Li}$ and ${ }^{7} \mathrm{Be}$ are negligible compared with the hydrodynamics (rise time in temperature)[8]. Even though some nuclear reaction rates are still uncertain, leaks from the $\mathrm{CNO}$ cycle are negligible at novae temperatures. In particular, experimental data on the ${ }^{15} \mathrm{O}(\alpha, \gamma){ }^{19} \mathrm{Ne}[24]$ and ${ }^{19} \mathrm{Ne}(\mathrm{p}, \gamma){ }^{20} \mathrm{Ne}$ [25] are now sufficient to rule out any significant nuclear flow out the CNO cycle. Production of heavier elements rely on the presence of ${ }^{20-22} \mathrm{Ne},{ }^{23} \mathrm{Na},{ }^{24-26} \mathrm{Mg}$ and ${ }^{27} \mathrm{Al}$ in ONe white dwarfs. 


\section{${ }^{22} \mathrm{Na}$ production}

The decay of ${ }^{22} \mathrm{Na}\left(\tau_{1 / 2}=2.6 \mathrm{y}\right)$ is followed by the emission of a $1.275 \mathrm{MeV}$ photon. Observations have up to now only provided upper limits, compatible with model predictions, for this gamma ray emission. Its detection remains a goal for present (Integral) and future gamma-ray observatories. Calculating the expected ${ }^{22} \mathrm{Na}$ yields used to be hampered by the nuclear uncertainties on the ${ }^{21} \mathrm{Na}(\mathrm{p}, \gamma){ }^{22} \mathrm{Mg}$ and ${ }^{22} \mathrm{Na}(\mathrm{p}, \gamma)^{23} \mathrm{Mg}$ reaction rates[10].

Destruction of ${ }^{22} \mathrm{Na}$ in nova proceeds through the ${ }^{22} \mathrm{Na}(\mathrm{p}, \gamma)^{23} \mathrm{Mg}$ reaction. Since the NACRE compilation a Gammasphere experiment[26] and a $\beta$-decay experiment[27] have improved the ${ }^{23} \mathrm{Mg}$ spectroscopy, reducing by a factor of $\sim 10$ the uncertainty below $10^{8} \mathrm{~K}$. Unfortunately, they also discovered a new level which could lead to a yet unobserved resonance at $190 \mathrm{keV}$. The rate uncertainty at nova temperatures remains large: a factor of $\sim 10$.

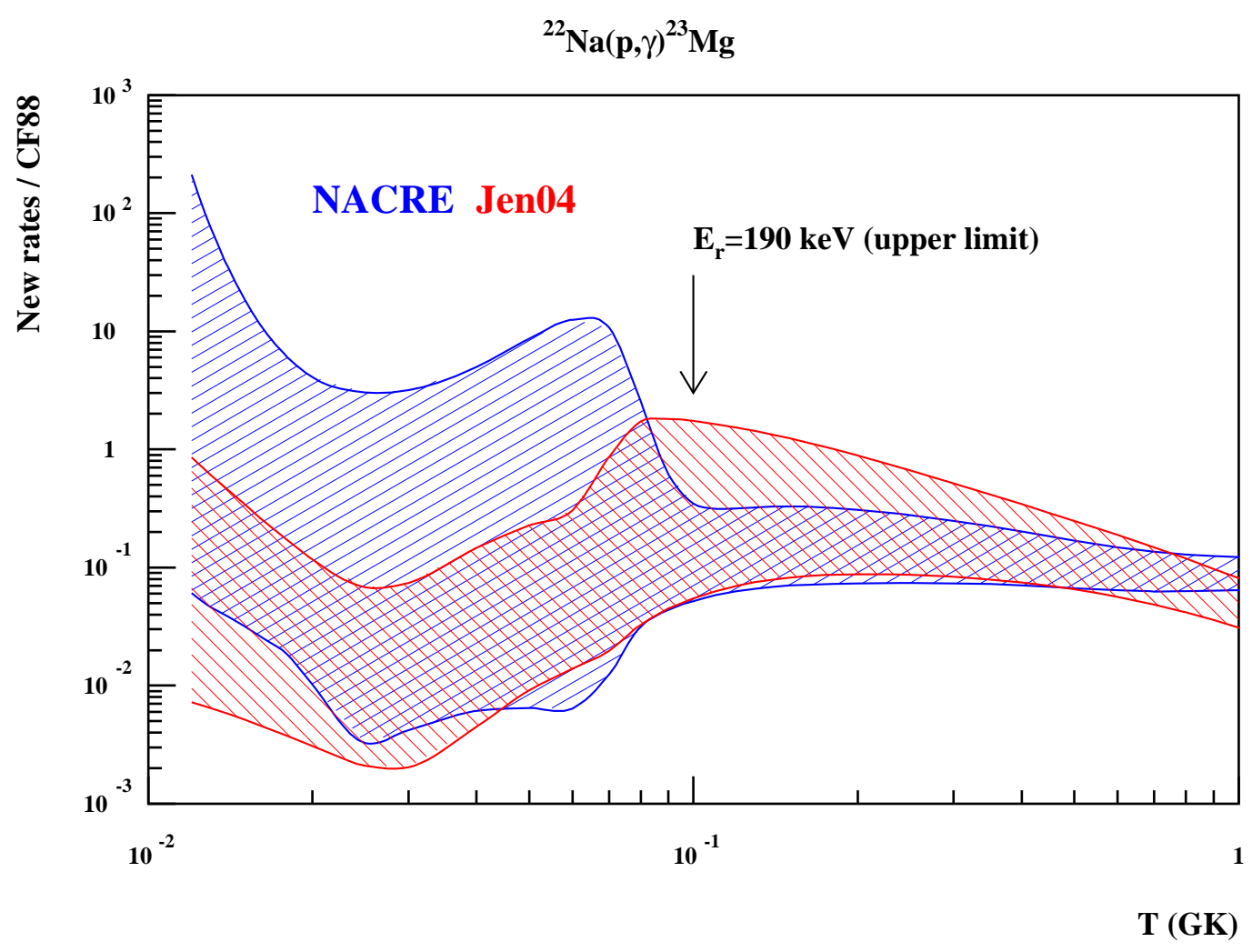

FIGURE 5. (On-line only.) Evolution of the ${ }^{22} \mathrm{Na}(\mathrm{p}, \gamma)^{23} \mathrm{Mg}$ reaction rate uncertainty since Ref. [10].

Photodisintegration of ${ }^{22} \mathrm{Mg}$, important at nova temperatures, prevents further processing but the ${ }^{21} \mathrm{Na}(\mathrm{p}, \gamma)^{22} \mathrm{Mg}$ reaction remains important for ${ }^{22} \mathrm{Na}$ production. It is a branching point between ${ }^{21} \mathrm{Na}(\mathrm{p}, \gamma)^{22} \mathrm{Mg}\left(\beta^{+}\right)^{22} \mathrm{Na}$ and ${ }^{21} \mathrm{Na}\left(\beta^{+}\right)^{21} \mathrm{Ne}(\mathrm{p}, \gamma)^{22} \mathrm{Na}$, affecting the timescale and hence the ${ }^{22} \mathrm{Na}$ production[10]. The uncertainty on this rate used to come from the unknown contributions of three unobserved resonances associated with the $E_{X}=5.714,5.837$ and $5.962 \mathrm{MeV}^{22} \mathrm{Mg}$ levels. Thanks to experiments conducted at 
the TRIUMF-ISAC facility with a ${ }^{21} \mathrm{Na}$ beam, $\left.i\right)$ the $E_{R}=206 \mathrm{keV}\left(E_{X}=5.714 \mathrm{MeV}\right)$ resonance strength has been precisely measured[28] and $i i$ ) the contribution of the others was found to be negligible[29].

\section{${ }^{26} \mathrm{Al}$ production}

With its long lifetime, ${ }^{26 g . s .} \mathrm{Al}\left(\tau_{1 / 2}=0.717 \mathrm{My}\right)$ a single nova gamma ray emission $(1.809 \mathrm{MeV})$ is far too faint to be observable but novae can contribute to the accumulation of this isotope in the Galaxy. The major nuclear uncertainties affecting its production were identified to be the ${ }^{25} \mathrm{Al}(\mathrm{p}, \gamma){ }^{26} \mathrm{Si}$ and ${ }^{26 g . s .} \mathrm{Al}(\mathrm{p}, \gamma){ }^{27} \mathrm{Si}[10]$.

The ${ }^{26 g . s .} \mathrm{Al}(\mathrm{p}, \gamma){ }^{27} \mathrm{Si}$ reaction governs ${ }^{26} \mathrm{Al}$ ground state destruction in novae. For nucleosynthesis calculations, its rate was often adopted from the unpublished work of Vogelaar. The NACRE compilation excluding unpublished results assigns a large uncertainty to this rate at nova temperature. The strength of the $E_{R}=188 \mathrm{keV}$ resonance was at the origin of this uncertainty and influenced directly the ${ }^{26} \mathrm{Al}$ production [10]. It has now been measured directly with a ${ }^{26} \mathrm{Al}$ beam at the TRIUMF-ISAC facility and found[30] to be within a factor of 1.6 from the unpublished Vogelaar's value. Nevertheless, the uncertainty remains large (orders of magnitudes) below $10^{8} \mathrm{~K}$ because of the lack of information on lower energy resonances.

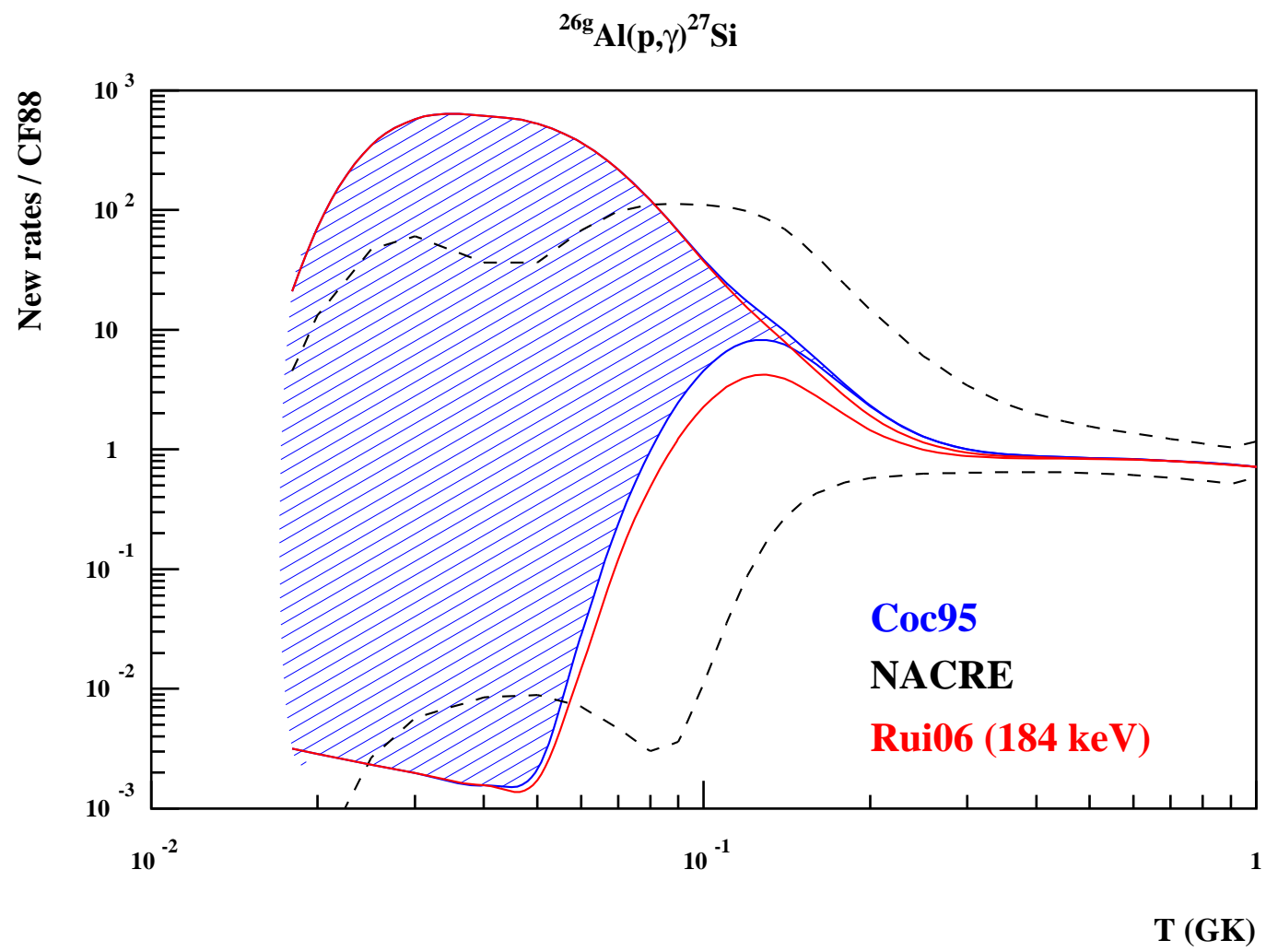

FIGURE 6. (On-line only.) Evolution of the ${ }^{26} \mathrm{Ap}(\mathrm{p}, \gamma)^{27} \mathrm{Si}$ reaction rate uncertainty since Ref. [10]. 
Depending on the initial ${ }^{24} \mathrm{Mg}$ abundance, the ${ }^{25} \mathrm{Al}(\mathrm{p}, \gamma){ }^{26} \mathrm{Si}$ can have a crucial role in the formation of ${ }^{26 g . s .} \mathrm{Al}$ as it provides a diversion from the ${ }^{24} \mathrm{Mg}(\mathrm{p}, \gamma){ }^{25} \mathrm{Al}\left(\beta^{+}\right){ }^{25} \mathrm{Mg}(\mathrm{p}, \gamma){ }^{26 g . s .}$ Al flow. Following ${ }^{25} \mathrm{Al}(\mathrm{p}, \gamma),{ }^{26} \mathrm{Si}$ can either decay to the short lived isomeric ${ }^{26} \mathrm{Al}$ level or be destroyed by subsequent proton capture[31]. In either cases, it bypasses the long lived ${ }^{26} \mathrm{Al}$ and gamma emitting ground state. (At nova temperature, ${ }^{26} \mathrm{Al}$ isomer and ground states have to be considered as separate species[32].) Orders of magnitudes uncertainties arose from missing ${ }^{26} \mathrm{Si} \mathrm{levels,} \mathrm{in}$ particular a $3^{+}(\ell=0)$. Spectroscopic studies [33, 34, 35, 36, 37] of ${ }^{26} \mathrm{Si}$ have lead to the localization of a $4^{+}$and a $1^{+}$level and the probable localization of the $3^{+}$level at $E_{X}$ $=5.912 \mathrm{MeV}$ and $0^{+}$level at $E_{X}=5.946 \mathrm{MeV}$. The corresponding resonance strengths have not been measured, but the uncertainty on this rate has been considerably reduced.
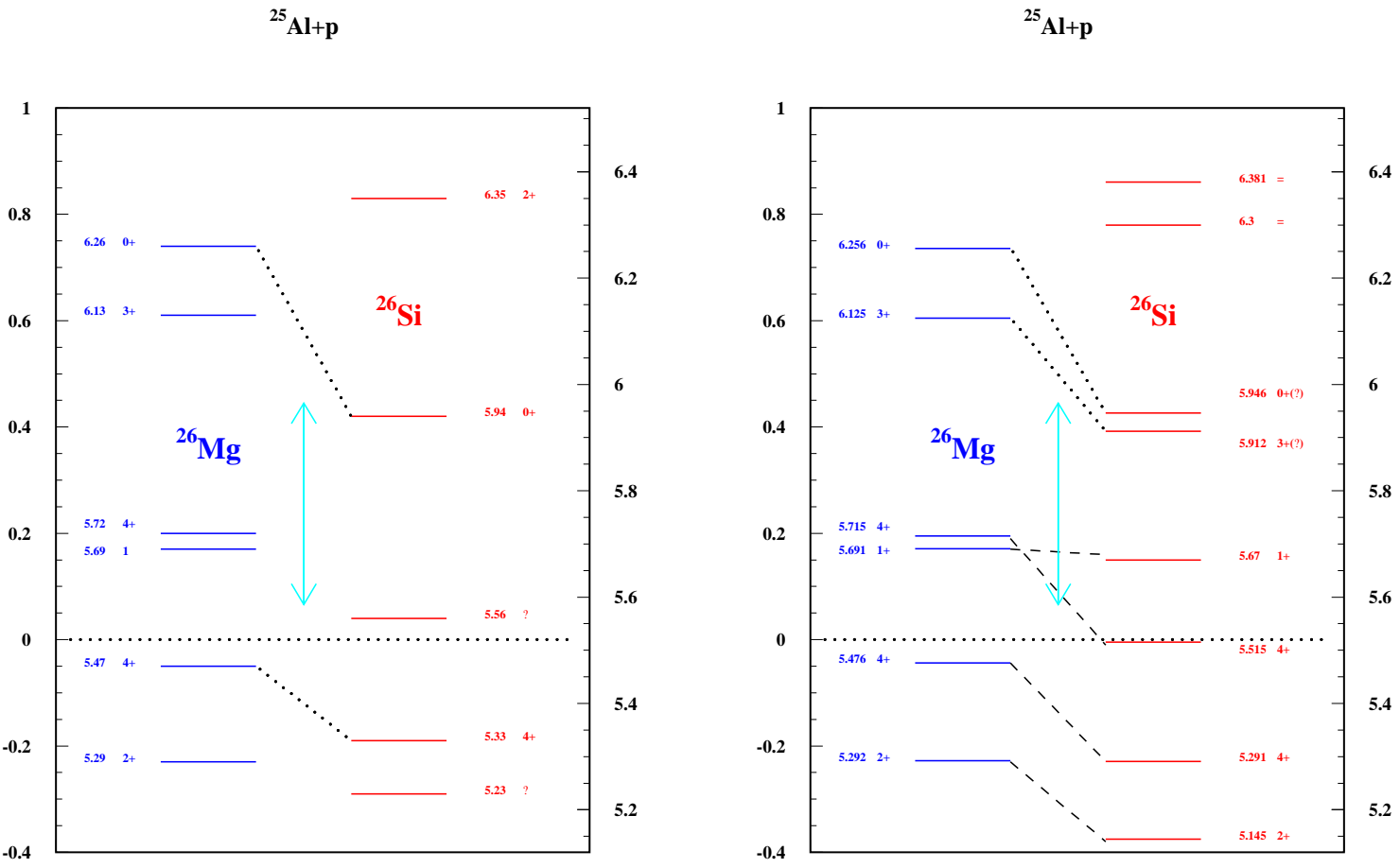

FIGURE 7. (On-line only.) Progress in ${ }^{26} \mathrm{Si}$ spectroscopy for the ${ }^{25} \mathrm{Al}(\mathrm{p}, \gamma){ }^{26} \mathrm{Si}$ reaction rate since Ref. [10]. The arrow represent the region of interest for nova nucleosynthesis.

\section{Heavy elements production}

There is normally no significant amount of elements beyond aluminum found in white dwarfs composition. Hence, the production of "heavy elements", i.e. from silicon to argon, rely on the nuclear flow out of the $\mathrm{Mg}$-Al region through ${ }^{28} \mathrm{Si}$ and subsequently through ${ }^{30} \mathrm{P}$ whose relatively long lifetime $\left(\tau_{1 / 2}=2.5 \mathrm{mn}\right)$ may halt the flow unless the ${ }^{30} \mathrm{P}(\mathrm{p}, \gamma){ }^{31} \mathrm{~S}$ is fast enough. This reaction is also important to calculate the silicon 
isotopic ratios to be compared to values measured in some presolar grains that may have a nova origin[38]. Due to the limited spectroscopic data available for the ${ }^{31} \mathrm{~S}$ nucleus, up to now an Hauser-Feshbach rate was used in nova nucleosynthesis calculations. This statistical model, assuming a high level density, is certainly not appropriate for such a low mass nucleus and temperature domain. The uncertainty was difficult to determine but two orders of magnitudes was the usual estimate. The ${ }^{31} \mathrm{~S}$ spectroscopy is not yet completed in the range of excitation energy important for nova but about ten levels have been observed[39, 40, 41, 42, 43] in that region with spins and parities generally assigned. The relatively high level density prevented all these levels to be experimentally resolved so that confirmations would be welcomed. The resonance strength used to calculate the thermonuclear reaction rate are also obtained by assuming typical values for spectroscopic factors. The resulting reaction rate, even though still uncertain, present a significant improvement and seems[43] close to the Hauser-Feshbach one used in previous nucleosynthesis calculations.

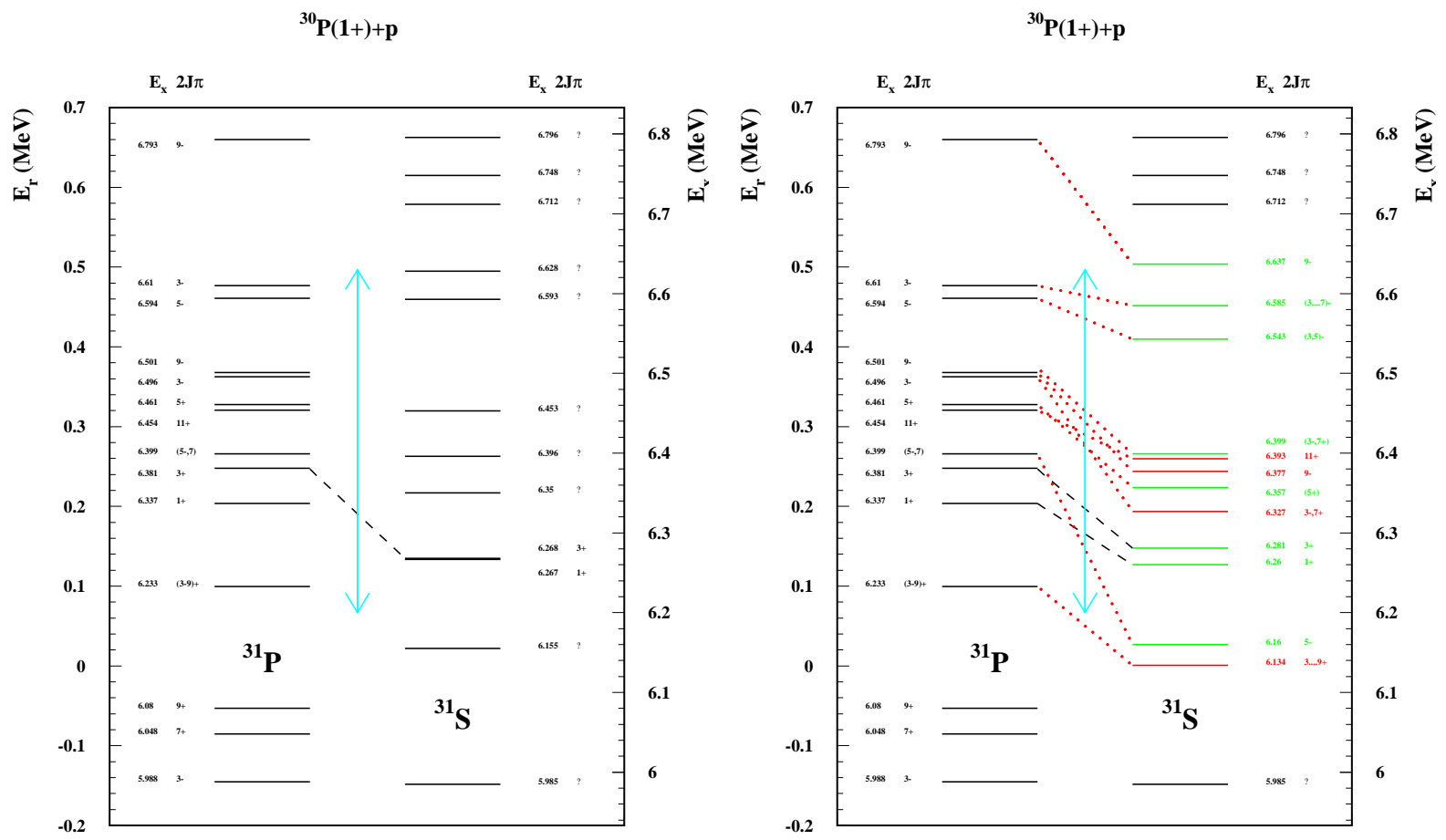

FIGURE 8. (On-line only.) Progress in ${ }^{31} \mathrm{~S}$ spectroscopy for the ${ }^{30} \mathrm{P}(\mathrm{p}, \gamma){ }^{31} \mathrm{~S}$ reaction rate since Ref. [11].

\section{CONCLUSIONS}

Detailed calculations performed with the SHIVA hydrodinamical code have enable the identification of nuclear uncertainties affecting nova nucleosynthesis. We see 
that less than ten years after, great progress have been made thanks to experimental efforts, in particular for the ${ }^{17} \mathrm{O}(\mathrm{p}, \gamma){ }^{18} \mathrm{~F},{ }^{17} \mathrm{O}(\mathrm{p}, \alpha){ }^{14} \mathrm{~N},{ }^{18} \mathrm{~F}(\mathrm{p}, \gamma){ }^{19} \mathrm{Ne},{ }^{18} \mathrm{~F}(\mathrm{p}, \alpha){ }^{15} \mathrm{O}$, ${ }^{21} \mathrm{Na}(\mathrm{p}, \gamma){ }^{22} \mathrm{Mg},{ }^{22} \mathrm{Na}(\mathrm{p}, \gamma){ }^{23} \mathrm{Mg}{ }^{25} \mathrm{Al}(\mathrm{p}, \gamma){ }^{26} \mathrm{Si},{ }^{26 g . s .} \mathrm{Al}(\mathrm{p}, \gamma){ }^{27} \mathrm{Si}$ and ${ }^{30} \mathrm{P}(\mathrm{p}, \gamma){ }^{31} \mathrm{~S}$ reactions that were identified as the most influential. However, further efforts are required for the ${ }^{22} \mathrm{Na}(\mathrm{p}, \gamma){ }^{23} \mathrm{Mg},{ }^{25} \mathrm{Al}(\mathrm{p}, \gamma){ }^{26} \mathrm{Si},{ }^{30} \mathrm{P}(\mathrm{p}, \gamma){ }^{31} \mathrm{~S}$ reactions and especially for the ${ }^{18} \mathrm{~F}(\mathrm{p}, \alpha){ }^{15} \mathrm{O}$ reaction. For this last reaction where contribution of interfering broad resonance tails are essential, progress should come from direct measurements with intense ${ }^{18} \mathrm{~F}$ beam (TRIUMF) or from indirect (THM[44]) measurement planned at the CRIB of the Center for Nuclear Studies (Wako).

\section{ACKNOWLEDGMENTS}

I am indebted to Margarita Hernanz and Jordi José for a now more than twelve years collaboration on nova nucleosynthesis and to Nicolas de Séréville for frequent discussions. Many thanks also to Carmen Angulo, Christian Iliadis, Faïrouz Hammache, François de Oliveira Santos and Claudio Spitaleri for long time collaborations.

\section{REFERENCES}

1. S. Starrfield, J.W. Truran, W.M. Sparks, and G.S. Kutter, Astrophys. J., 176, 169 (1972).

2. R.D. Gehrz, J.W. Truran, R.E. Williams, and S. Starrfield, Publ. Astron. Soc. Pacific, 743, 3-26 (1998).

3. J. José and M. Hernanz, Astrophys. J., 494, 680 (1998).

4. J. José and M. Hernanz, J. Phys., G34, R431-R458 (2007).

5. L. van Wormer, J. Goerres, C. Iliadis, M. Wiescher and F.-K. Thielemann, Astrophys. J., 432, 326 (1994).

6. A. Coc, R. Mochkovitch, Y. Oberto, J.-P. Thibaud and E. Vangioni-Flam, Astron. Astrophys., 299, 479-492 (1995).

7. C. Iliadis, A. Champagne, J. José, S. Starrfield, and P. Tupper, Astrophys. J. S., 142, 105 (2002).

8. M. Hernanz, J. José, A. Coc, and J. Isern, Astrophys. J., 465, L27-L30 (1996) [astro-ph/9604102].

9. A. Coc, M. Hernanz, J. José, and J.P. Thibaud (CJHT), Astron. Astrophys., 357, 561-571 (2000) [astro-ph/0003166].

10. J. José, A. Coc and M. Hernanz, Astrophys. J., 520, 347-360 (1999) [astro-ph/9902357].

11. J. José, A. Coc, and M. Hernanz Astrophys. J., 560, 897-906 (2001) [astro-ph/0106418].

12. J. Gomez-Gomar, M. Hernanz, J. José and J. Isern, Mon. Not. R. Astron. Soc., 296, 913 (1998).

13. S. Utku, J.G. Ross, N.P.T. Bateman, D.W. Bardayan, A.A. Chen et al., Phys. Rev., C57, 2731 (1998).

14. N. de Séréville, A. Coc, C. Angulo, M. Assunção, D. Beaumel et al., Phys. Rev.,C67 052801(2003)[nucl-ex/0304014] and Nucl. Phys., A791, 251-266 (2007) [nucl-ex/0702034].

15. R.L.Kozub, D.W.Bardayan, J.C.Batchelder, J.C.Blackmon, C.R.Brune et al., Phys. Rev., C71, 032801 (2005) and Phys. Rev., C73, 044307 (2006).

16. R.Coszach, M.Cogneau, C.R.Bain, F.Binon, T.Davinson et al. Phys. Lett., 353B, 184 (1995); see also references in Ref. [14].

17. D.W.Bardayan, J.C.Batchelder, J.C.Blackmon, A.E.Champagne, T.Davinson et al., Phys. Rev. Lett., 89, 262501 (20002) and references therein.

18. N. de Séréville, C. Angulo, A. Coc, N. L. Achouri, A. Casarejos et al., submitted.

19. M.Dufour \& P.Descouvemont, Nucl. Phys., A785, 381 (2007).

20. F. de Oliveira-Santos and J.C. Dalouzy, private communication.

21. C. Angulo, M. Arnould, M. Rayet, P. Descouvemont, D. Baye et al. (NACRE), Nucl. Phys., A656, 3-183 (1999) and http://pntpm.ulb.ac.be/nacre.htm. 
22. A. Chafa, V. Tatischeff, P. Aguer, S. Barhoumi, A. Coc et al., Phys. Rev. Lett., 95, 031101 (2005) and Phys. Rev., C75, 035810 (2007).

23. C. Fox, C. Iliadis, A.E. Champagne et al., Phys. Rev. Lett., 93, (2004) 081102 and Phys. Rev., C71, 055801 (2005).

24. W.P. Tan, J.L. Fisker, J. Görres, M. Couder, and M. Wiescher, Phys. Rev. Lett., 98, 242503 (2007).

25. M. Couder, C. Angulo, E. Casarejos, P. Demaret, P. Leleux, and F. Vanderbist, Phys. Rev., C69, 022801 (2004).

26. D.G. Jenkins, C.J. Lister, R.V.F. Janssens, T.L. Khoo, E.F. Moore et al., Phys. Rev. Lett., 92, 031101 (2004)

27. V.E. Iacob, Y. Zhai, T. Al-Abdullah, C. Fu, J.C. Hardy et al., Phys. Rev., C74, 045810 (2006).

28. S. Bishop, R.E. Azuma, L. Buchmann, A.A. Chen, M.L. Chatterjee et al., Phys. Rev. Lett., 90, 162501 (2003).

29. J.M. D’Auria, R.E. Azuma, S. Bishop, L. Buchmann, M.L. Chatterjee et al., Phys. Rev., C69, 065803 (2004).

30. C. Ruiz, A. Parikh, J. José, L. Buchmann, J.A. Caggiano et al., Phys. Rev. Lett., 96, 252501 (2006).

31. Y. Togano et al., these proceedings.

32. A. Coc, M.-G. Porquet and F. Nowacki Phys. Rev., C61, 015801 (2000) [astro-ph/9910186.

33. D.W. Bardayan, J.C. Blackmon, A.E. Champagne, A.K. Dummer, T. Davinson et al., Phys. Rev., C65, 032801 (2002).

34. J.A. Caggiano, W. Bradfield-Smith, R. Lewis, P.D. Parker, D.W. Visser et al., Phys. Rev., 65, 055801 (2002).

35. Y. Parpottas, S.M. Grimes, S. Al-Quraishi, C.R. Brune, T.N. Massey et al., Phys. Rev., C70, 065805 (2004).

36. D.W. Bardayan, J.A. Howard, J.C. Blackmon, C.R. Brune, K.Y. Chae et al., Phys. Rev., C74, 045804 (2006).

37. D. Seweryniak, P.J. Woods, M.P. Carpenter, T. Davinson, R.V.F. Janssens et al., Phys. Rev., C75, 062801 (2007).

38. S. Amari, X. Gao, L.R. Nittler, E. Zinner, J. José et al., Astrophys. J., 551, 1065 (2001).

39. D.G. Jenkins, C.J. Lister, M.P. Carpenter, P. Chowdhury, N.J. Hammond et al., Phys. Rev., C72, 031303 (2005)

40. D.G. Jenkins, A. Meadowcroft, C.J. Lister, M.P. Carpenter, P. Chowdhury et al., Phys. Rev., C73, 065802 (2006).

41. A. Kankainen, T. Eronen, S.P. Fox, H.O.U. Fynbo, U. Hager et al., European Physical Journal, A27, 67 (2006).

42. Z. Ma, D.W. Bardayan, J.C. Blackmon, R.P. Fitzgerald, M.W. Guidry et al., Phys. Rev., C76, 015803 (2007).

43. C. Wrede, J.A. Caggiano, J.A. Clark, C. Deibel, A. Parikh, and P.D. Parker, Phys. Rev., C76, 052802(R) (2007).

44. C. Spitaleri, these proceedings; L. Sergi et al., these proceedings. 